\title{
TIME SERIES ANALYSIS IN SELF-REGULATING SYSTEMS
}

\author{
V. F. Fedorov \\ Moscow Institute of Physics and Technology (State University), 9 Institutsky Per., \\ Dolgoprudny, Moscow region 141700, Russia \\ Peoples' Friendship University of Russia, Miklukho-Maklaya str. 6, Moscow 117198, Russia
}

The paper is received on April 23, 2019

\begin{abstract}
This paper describes a new approach to time series analysis of quantitative parameters of functional diagnostics signals. The normalization of measured values is introduced, which reduces the influence of individual differences when comparing data of different patients In addition, the normalization allows to build classification rules based on multivariate statistics and draw distinctions between heterogeneous groups more precisely. The effectiveness of normalization algorithms tested on the time series of durations of cardiac cycles, systolic output and peripheral vascular resistance. We suggest using this approach for time series analysis of quantitative parameters of other self-regulating systems.
\end{abstract}

Keywords: self-regulating systems; time series analysis; functional diagnostics.

\section{Introduction}

Functional diagnostics in its modern sense arose in the early 20th century. The first instrumental functional diagnostics method was electrocardiography (ECG) invented in 1902-1906 by Willem Einthoven who was afterwards awarded the Nobel Prize for his discovery in 1924 [1, 2]. Mathematical analysis of electrocardiograms allowed him to make significant clarifications for interpretation of the heart electrical activity. In the same 1906, he initiated telemedicine by transmitting the ECG signal by the telephone for diagnostic purposes for the first time [3]. His description of ECG signals as a quasi-periodic sequence of "waves", "intervals", and "segments" corresponding to certain phases of cyclic heart activity are used in medicine at the present time, i.e. for more than 110 years.

As normal and pathological physiology of the cardiovascular system were studied, the diagnostic equipment was developed and improved, new instrumental 
functional diagnostics methods emerged and evolved describing various quasiperiodic processes: kinetocardiography and ballistocardiography, apexcardiography and seismocardiography, phonocardiography and echocardiography, rheovasography and photoplethysmography, sphygmoarteriography and tacho-oscillography (according to Savitskiy).

\section{Quasi-periodicity}

We are talking about the quasi-periodicity of rhythmic processes in the heart and blood vessels because almost every cardiovascular system cycle differs from the preceding and subsequent ones in duration in a healthy organism. This phenomenon was described as early as the 19th century by Einbrodt [4]. Later, a number of researchers continued studies into rhythmical processes of the human cardiovascular system and relations between their aperiodicity and various effects [5-11], and, in 1951, aperiodicity itself became an object of study [12]. In 1962, the first mathematical model of cardiac rhythm control was published [13]. Since 1965, works on the clinical significance of heart rate variations have been published [14]. A team of scientists led by academician V.V. Parin laid foundation research on variations in the heart rate of a healthy person [15]. With the development of measurement and computing technologies, the analysis of human heart rate variations became more widespread, and in 1996 it was "standardized" at the international level [16].

It would seem that over the past one and a half centuries of studying the time series of cardiocycle durations, all problems have long been resolved and all methods of studying rhythmic processes in a living organism have long been optimized. However, getting acquainted with both individual articles and with the "standard" shows that this is far from the case.

The main unresolved problem is the normalization of parameters on the individual characteristics of the patient.

\section{Anthropometric differences}

First and foremost, these are anthropometric differences: height, weight, body type. Cardiac rhythm dependence on the body weight is described, for example, by Schmidt-Nielsen [17] who refers to an older paper published by Brody in 1945. They 
define heart rate $(\mathrm{HR}, 1 / \mathrm{min})$ by the following formula: $\mathrm{HR}=241 \times \mathrm{BW}^{\wedge}-0.25$, where BW is the body weight in $\mathrm{kg},-0.25$ is the exponent.

At the same time, this is not taken into account in the "standard", therefore, it is incorrect to compare the results of patients significantly differing in body weight using the described methods.

Moreover, there is an expressed dependence between HR and body type, as, according to G.M. Akhmadiyev: "The study showed that children of hypersthenic type had a relatively low average HR value of $68 \mathrm{bpm}(\mathrm{p}<0.05)$, while the values of asthenic and normosthenic types were $75.71 \mathrm{bpm}(\mathrm{p}<0.01)$ and $80.34 \mathrm{bpm}(\mathrm{p}<0.01)$, respectively" [18].

There are also significant differences in cardiovascular system rhythmics depending on the predominant autonomic regulation type (normotonic, vagotonic, sympathotonic), which is described in many studies [19, 20].

Autonomic regulation in women of fertile age, including cardiovascular system activity regulation, depends on the menstrual cycle phase, therefore, rhythmical processes of a female organism can be very different from those of males with all other conditions being equal both in health and in disease [21, 22].

The four factors mentioned above, which affect the quantitative parameters of quasi-periodic processes in the human body make the task of classification by these parameters both under normal and pathological conditions rather difficult.

Is it possible to take into account all these factors or to normalize the time series of quantitative parameters in such a way that the comparison and classification problems are significantly simplified and their solutions become more correct?

\section{Research and results}

As actual consideration of all variants and combinations thereof for the above factors is a complicated task, we have introduced internal normalization for both analysis varying conditions of one and the same human organism and comparison and classification of different people. Our normalization was introduced based on the following considerations of physiological cybernetics: 
1) Regulatory impacts of the vegetative nervous system sympathetic and parasympathetic parts are commutative but not additive, that is, if necessary, heart rate increases (or decreases) not "by X beats per minute", but in "Y times".

2) Regulation of actuators is based on a balance of positive and negative feedbacks.

On that basis, it is more logical to analyze not the sequence of individual cardiac cycle durations, which in each patient is individual, but the sequence of the each cardiac cycle duration ratio to the previous one, which reflects the abovementioned principles of regulation. To separate effects of positive and negative feedbacks on the actuator, we decided to take the logarithm of these relations. In other words, the sequence of $\mathrm{Ti}(\mathrm{t})$ for the heart rate was replaced by the sequence of $\square \mathrm{i}=\lg (\mathrm{Ti} / \mathrm{Ti}-1)$.

Let's consider what we got as a result.

Figure 1 shows a diagram of a patient's cardiac cycle durations sequence during a three-phase active orthostatic test (lying-standing-lying). It can be clearly seen that, in lying positions (test phases 1 and 3), cardiac cycle duration exceeds 1000 milliseconds, i.e. HR is less than 60 per minute (bradycardia). Figure 2 shows a diagram of relative variations logarithms of the same sequence. While in the first diagram all values are positive and differ from one patient to another and from one state of the same patient to another, in the second diagram, values are distributed almost evenly in relation to the zero line and mostly differ among functional states but not among patients.

As per Figure 3, graphical representation of distribution of initial values (the left histogram) only shows its difference from the normal one, while frequency distribution of standardized values (the right diagram) distinguishes between results of accelerating (to the left of zero) and decelerating (to the right of zero) regulation effects. In the case of heart rate, we can say that the left and right halves of the diagram of normalized values probability density show the effect of the vegetative nervous system sympathetic and parasympathetic parts, respectively. The example provided clearly shows the autonomic imbalance. 


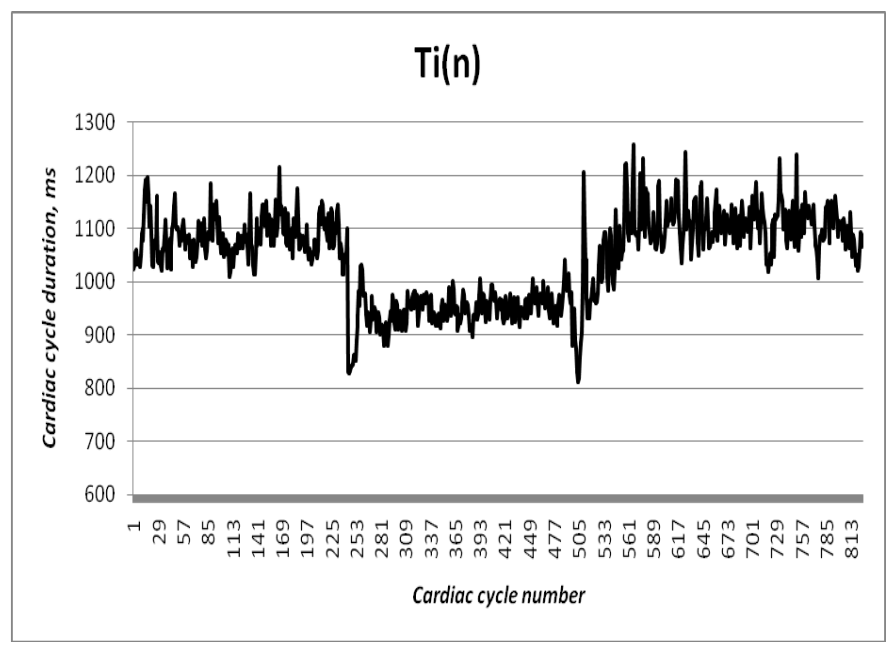

Fig. 1. Diagram of a patient's cardiac cycle durations times series during a threephase active orthostatic test (lying-standing-lying).

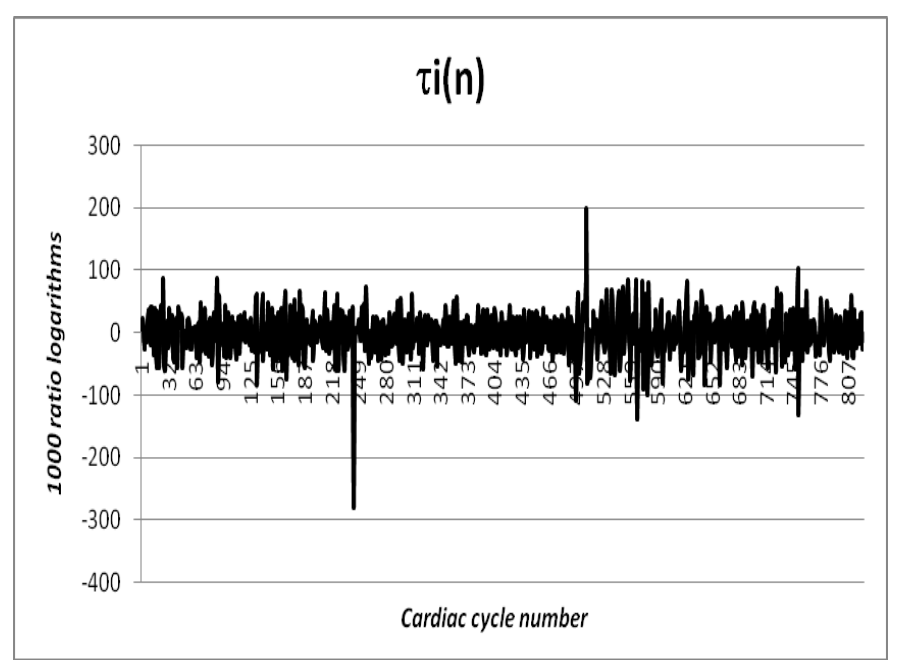

Fig. 2. Diagram of logarithms of relative variations of the same series.

\section{Серия Nㅗ 1 (50--199)}

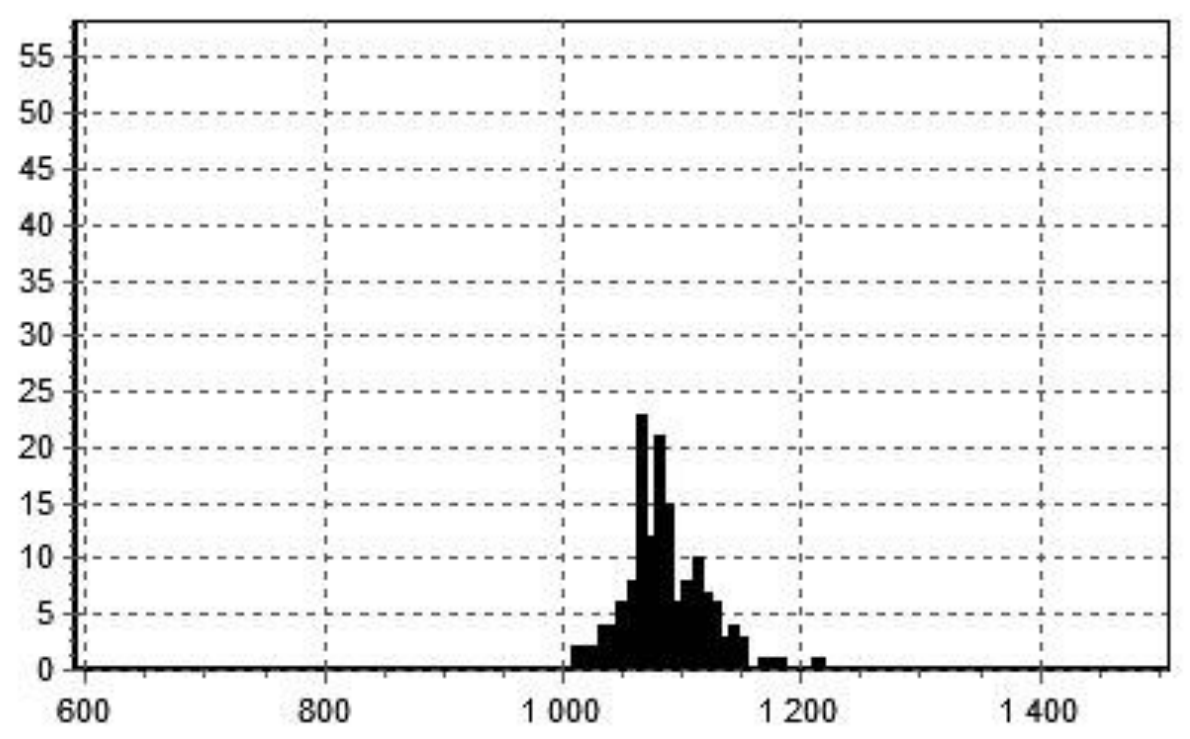




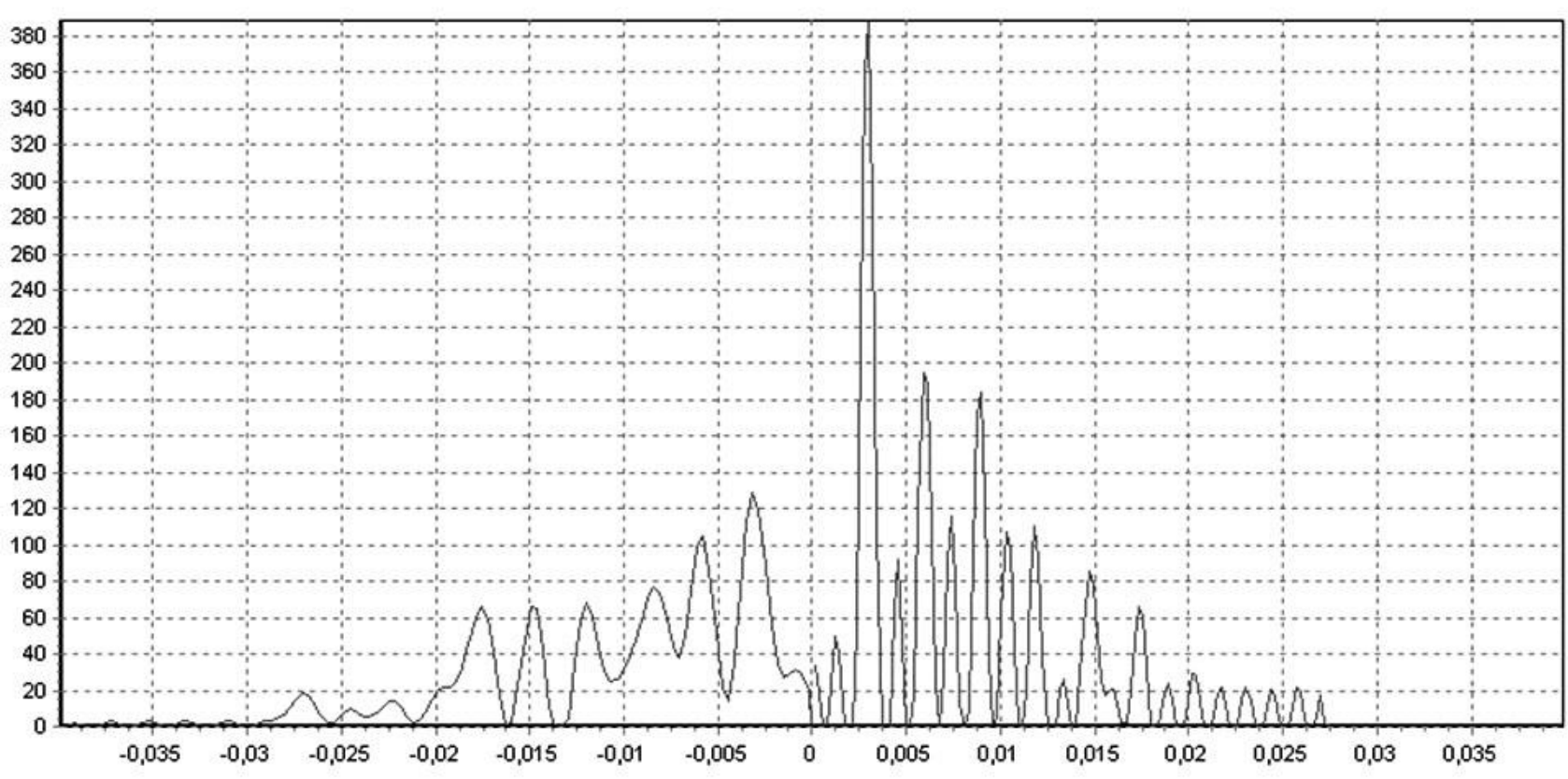

Fig. 3. Diagrams of statistical distributions of original (on the left) and normalized values (approximation using algorithms of [23] on the right) of a fragment of the same time series.

To valuate regulation effects on the process represented by the time series of quantitative parameters, we introduced two new parameters: the reduction and increase factors of the regulated values ( $\mathrm{Kn}$ and $\mathrm{Kp}$, respectively). They are calculated by processing fragments of normalized time series with negative $(\mathrm{Kn})$ and positive (Kp) values using the following formula:

$$
K=\frac{1}{\sqrt{|M| \times \sigma}},
$$

where $\mathrm{M}$ is the statistical mode, $\sigma$ is the standard deviation in the calculation window.

Figure 4 shows diagrams of $\mathrm{Kn}$ and $\mathrm{Kp}$ values obtained by processing time series of patient cardiac cycle durations during a three-phase active orthostatic test (lying-standing-lying) in a moving window of 150 values with a shift of 10 (on the left), and a 3D diagram of approximating distributions trend (on the right).

Similar results were obtained by us also in the analysis of time series of the stroke volume and the total peripheral resistance of small diameter vessels. Study of the informative value of parameters of the normalized attribute space against the 
initial one showed that multivariate statistics methods give much better classification results for normalized values [24].
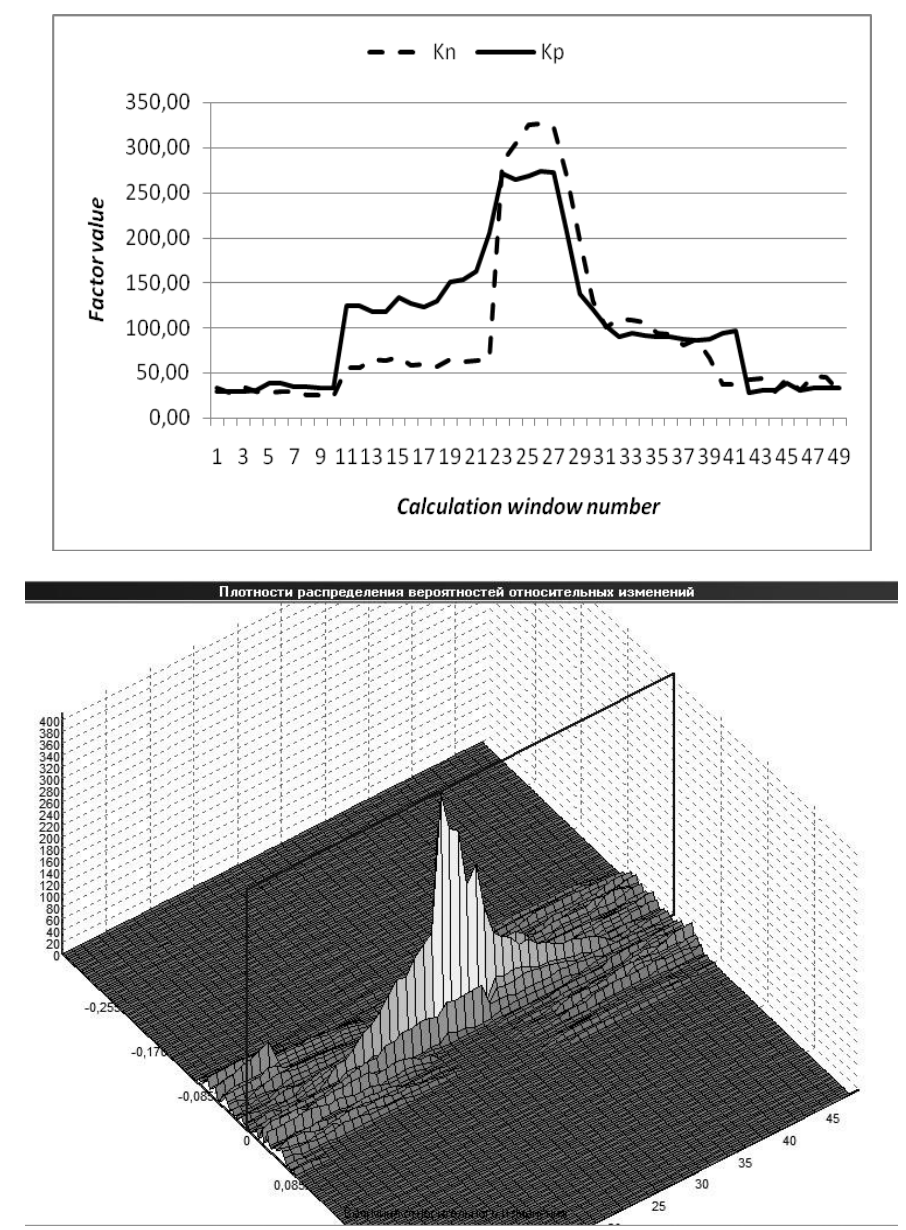

Fig. 4. Diagrams of Kn and Kp values during a three-phase active orthostatic test (lying-standing-lying) on the left, and a diagram of normalized values statistical distributions trend on the right. Along the $X$ axis: relative variation logarithm value;

$\mathrm{Y}$ axis: share of such values; $\mathrm{Z}$ axis: calculation window number (discrete time)

In view of the foregoing, we can assume that the same approach can also be used in analysis of other time series representing behavior of quantitative parameters in self-regulating systems.

\section{References}

1. Einthoven W. Galvanometrische registratie van het menschelijk electrocardiogram. Leiden: Eduard Ijdo, 1902. P. 101-107.

2. All Nobel Prizes on Physiology and Medicine. Site of Nobel Prize Organization Available at 


\section{https://www.nobelprize.org/nobel_prizes/medicine/laureates/1924/press.html}

(23.01.2018)

3. Einthoven W. Le télécardiogramme. Paris: Arch Int Physiol, 1906. No 4. P. 132-164.

4. Einbrod. Über den Einfluß der Atembewegung auf Herzschlag und Blutdruck. Sber. Akad. Wiss. Wien; Math. Nat. Kl., 2. Abt., 40 (1860), S. 361-418.

5. Hunt, R.J. Experiments on the relation of the inhibitory to the acceleration nerves of the heart. J.Exp. Med. 1897, No.2, $151-179$.

6. Bainbridge, F.A. The influence of venous filling upon the rate of the heart. $J$. Physiol. (London), 1915, Vol.50. pp. 65.

7. Bainbridge, F.A. The relation between respiration and pulse-rate. J. Physiol. (London), 1920, Vol. 54, pp. 192.

8. Boas EP, Goldschmidt EF. eds. The Heart Rate. Charles C Thomas. Springfield, Illinois, 1932.

9. Brown, G.L. and Eccles, J.C., The action of a single vagal volley on the rhythm of the heart beat. J. Physiol., 1934, Vol. 82, pp. $211-241$.

10.Rosenblueth, A. and Simeone, A.F., The interrelations of vagal and accelerator effects on cardiac rate. Amer. J. Physiol., 1934, Vol. 11, pp. 42-45.

11. Malmo RB, Shagass C. The variability of heart rate in relation to age, sex, and stress. J Appl Psychol., 1949, No. 2, p. 181-184.

12.Gol'dman L.N., i Merkul' V.E. Universal deviometer and the value of deviometry in assessing the functional state of the myocardium. Klinicheskaya meditsina Clinical Medicine, 1951, No. 1, p. 80 (In Russian).

13. Warner H.R., Cox A. Mathematical model of heart rate control by sympathetic and vagus efferent information. J. Appl. Physiol., 1962, No. 17, p. 349 - 355.

14. Hon E.H.; Lee S.T. Electronic evaluation of the fetal heart rate. American Joumal of Obstetlics and Gynecology, 1965, Vol. 87, No. 6, pp. 81426.

15. Parin V.V., Baevskij R.M., Volkov J.N., Gazenko O.G. [Cosmic cardiology] Leningrad, Medicina Publ., 1967, 206 p. (In Russian). 
16. Heart Rate Variability - Standards of Measurement, Physiological Interpretation, and Clinical Use, Task Force of the European Society of Cardiology and the North American Society of Pacing and Electrophysiology. Circulation, 1996, Vol. 93, 1043-1065.

17. Schmidt-Nielsen K. Scaling: Why is Animal Size so Important? Cambridge University Press, 1984, 241 pp.

18. Akhmadiev G.M. [Monitoring of the cardiovascular system of boys of secondary school age, depending on the types of constitutions and the nervous system] // Uchenye zapiski Kazanskoj gosudarstvennoj akademii veterinarnoj mediciny im. N.E. Baumana - Bulletin of Kazan State Academy of Ve terinary Medicine, 2016, Vol. 225, No. 1. pp. 3-7.(In Russian).

19. Shlyk N.I., Baevskij R.M. Heart Rate and type of vegetative regulation in assessing the level of health of the population and the functional preparedness of athletes. Materials of the VI All-Russian Symposium. Izhevsk, Publishing Center «Udmurtskij universitet», 2016. 608 p. (In Russian).

20. Dudnik E.N., Kalita A.V., Dibrova E.A., Fedorov S.M., Karimova I.M., Glazachev O.S., Sudakov K.V. Individual changes in the activity of the heart with the same physical effects in individuals with different tones of the autonomic nervous system. Bulletin of the Russian Academy of Medical Sciences, 2007, No. 3, pp. 39 - 43. (In Russian).

21. Ramalho ESV, Souza-Junior EL, Magnani M, Braga VA. Gender Differences in Heart Rate Variability Among Individuals Undergoing Regular Resistance Training Preliminary observations. Sultan Qaboos Univ Med J., 2017, Vol 17, No.2, pp. e209-e212. Doi: 10.18295/squmj.2016.17.02.012.

22. Rannelli LA1, MacRae JM1,2,3, Mann MC1,3, Ramesh S1,3, Hemmelgarn BR1,2,3,4, Rabi D1,3,4, Sola DY2,3, Ahmed SB1,2,3. Sex differences in associations between insulin resistance, heart rate variability, and arterial stiffness in healthy women and men: a physiology study. Can. J. Physiol. Pharmacol., 2017, Vol. 95, No. 4, pp. 349-355. Doi: 10.1139/cjpp-2016-0122. 
23. Vapnik V.N Algoritmi $i$ programmy dlya vosstanovleniya zavisimostey [Algorithms and programs for recovering dependencies]. Moscow, Nauka Publ., 1984, p. 688. (In Russian).

24. Fedorov V.F. Methodology of the analysis of the dynamics of the quantitative parameters of the functional diagnostics of the cardiovascular system. Doctoral thesis abstract. Moscow, 2014. (In Russian).

\section{For citation:}

V.F. Fedorov. Time series analysis in self-regulating systems Zhurnal Radioelektroniki - Journal of Radio Electronics. 2019. No.5. Available at http://jre.cplire.ru/jre/may19/9/text.pdf

DOI 10.30898/1684-1719.2019.5.9 